\title{
A Systematic Review on Rho-Kinase as a Potential Therapeutic Target for the Treatment of Erectile Dysfunction
}

This article was published in the following Dove Press journal: Research and Reports in Urology

\section{Kaleab Alemayehu Zewdie (ID Muluken Altaye Ayza (D) Bekalu Amare Tesfaye (D) Dawit Zewdu Wondafrash (ID Derbew Fikadu Berhe (D)}

Department of Pharmacology and Toxicology, School of Pharmacy, Mekelle University, Mekelle, Ethiopia
Correspondence: Kaleab Alemayehu Zewdie

Department of Pharmacology and

Toxicology, School of Pharmacy, Mekelle

University, P.O. Box: I87I, Mekelle,

Ethiopia

Tel +251921546562

Email kalxy2919@gmail.com
Background: Erectile dysfunction (ED) is a common clinical condition with limited treatment options. The main aim of the present systematic review was to synthesize information on Rho-kinase as a novel therapeutic approach for the treatment of ED.

Methods: We performed a systematic literature study in PubMed, Google Scholar and Scopus. Included studies were original articles studied the role of Rho-kinase in the pathogenesis and/or new treatment approach for ED in animal models and clinical studies, published between 2014 and 2019. Data derived from each study were study design used, interventions applied and main treatment outcomes. The quality of the selected articles was assessed by CAMARADES criteria and data were analyzed using descriptive statistics.

Results: A total of 1067 original articles were retrieved in the given period and eighteen papers met our inclusion criteria. Five articles explain the role of Rho-kinase in ED pathogenesis using different models such as cavernous nerve crush injury, heart failureinduced ED, vasculogenic and post-radical prostatectomy ED, diabetes-induced ED and agerelated ED. Other ten papers explain the role of novel drugs evaluated for ED treatment by targeting Rho-kinase as a new approach for ED therapy. The rest three papers discuss the role of plant extracts used by traditional society for the treatment of ED and assess their potential function in targeting Rho-kinase in animal models. The penile erectile functional index has shown that the ratio of intracavernosal pressure to mean arterial pressure (ICP/MAP) was decreased due to age and various chronic diseases. Whilst, ROCK I and ROCK II expression were increased. Western blot findings have also shown that ROCK II and MYPT-1 phosphorylation rates increased in cavernous tissue after ED induction. Besides, compounds which can inhibit the action of Rho-kinase activity showed relaxation of the corpus cavernosum, decrease in corporal fibrosis, and alleviate increased apoptosis and caspase- 3 activity in an NO-independent manner. Moreover, histological and molecular dysregulation have been improved by inhibition of Rho-kinase.

Conclusion: Targeting Rho-kinase may be a possible target for the treatment of ED secondary to specific causes, and Rho-kinase inhibitors may be a new drug family for the treatment of ED. However, this requires further studies for in-depth understanding.

Keywords: ROCK, Rho-kinase inhibitors, novel, therapeutic target, erectile dysfunction

\section{Introduction}

Rho Kinase (ROCK)

Rho-associated coil-forming protein kinase (ROCK) is derived from the ACG (cyclic adenosine monophosphate (cAMP)-dependent protein kinase A/protein kinase $\mathrm{C} /$ protein kinase $\mathrm{G}$ ) family of serine/threonine kinases and is activated by 
the guanosine triphosphate (GTP)-bound form of RhoA (the small monomeric G-protein). ${ }^{1,2}$ ROCK activity is regulated by its upstream regulators, the Rho-GTPases RhoA and RhoC, which belong to the Ras-superfamily. ${ }^{3}$ There are two isoforms, ROCK I and II, and are involved in various physiological and pathophysiological signaling pathways. $^{4,5}$

ROCKs have been studied extensively and known as the major downstream effectors of RhoA. ${ }^{6}$ It was involved in the generation of actin-myosin contractility and regulation of actin cytoskeleton dynamics. ${ }^{7}$ It has also crucial roles in cell proliferation, apoptosis, gene expression and multiple other common cellular functions, such as cell shape, motility, gene expression, secretion and proliferation. ${ }^{6,8,9}$ Moreover, it causes a contractile response in vascular smooth muscle cells by increasing $\mathrm{Ca}^{2+}$ sensitization. ${ }^{10}$

Rho-binding can modulate the autophosphorylation of the kinase activity of ROCK. ${ }^{11}$ However, RhoE (the small G protein) negatively control ROCK I activity by binding in $\mathrm{N}$ terminus and prevents RhoA binding to Rho-binding domain (RBD). ${ }^{7}$ Phosphoinositide-dependent kinase-1 can counteract the negative regulation produced by RhoE by preventing its binding to the $\mathrm{N}$ terminal. Other small $\mathrm{G}$ proteins (Rad and Gem) can bind and inhibit ROCK I and II activity by unknown mechanisms. ${ }^{7,12,13}$

Various experiments performed on humans, isolated tissues and genetically modified mouse models have shown that ROCKs have been involved in the pathophysiological pathways of different diseases. ${ }^{7,14,16}$ The two ROCK isoforms have been described as a promising and alternative target of inhibitory molecules for the wide variety of human diseases including erectile dysfunction. ${ }^{17,22}$

\section{Erectile Dysfunction}

Erectile dysfunction (ED) is the most common chronic illness affecting men and often associated with chronic diseases including hypogonadism, cardiovascular diseases and diabetes mellitus (DM). ${ }^{23,24}$ Age was also considered one of the main risk factors for $\mathrm{ED} .{ }^{25}$

Different mechanisms have been correlated with ED pathology, which involves physical (organic), emotional and psychological components. ${ }^{26,27}$ The most common reported mechanism were physical causes including neuropathies, neurological disorders, endocrinological disorders (hypogonadism or hyperprolactinaemia), vasculogenic ED (hypertension, atherosclerosis, and pelvic irradiation) and medication side effects due to anti-depressants, non-steroidal anti-inflammatory drugs, neuroleptics and antiepileptic medications. ${ }^{23,28,29}$ Stressful life events such as daily worries about work, money or other significant occurrences can be associated with emotional and psychological causes of sexual dysfunction. ${ }^{29}$ Ageing often associated with changes of the endocrine system (especially in elderly's). At an older age, the testicular Leydig cells do not produce sufficient testosterone and that may lead to ED. ${ }^{25}$ Moreover, there is also a decreased in blood supply to the penis. ${ }^{30}$

Different biochemical changes were produced in corporal smooth muscles by local and neuronal neurotransmitters through potassium channels, gap junctions and calcium channels. ${ }^{23,28,30}$ For example, the neurotransmitter nitric oxide (NO) has a principal role in mediating penile erection. Once synthesized, it diffuses into smooth muscle cells and, binds and stimulates guanyl cyclase, which increases cyclic guanosine monophosphate (cGMP) and activates protein kinase $\mathrm{G}$ (PKG). Then after, phosphorylates several intracellular proteins and ion transporters, resulting in hyperpolarization and decreased cytoplasmic $\mathrm{Ca},{ }^{2+}$ causing smooth muscle relaxation. ${ }^{31}$ In addition to the reduction of cytosolic $\mathrm{Ca}^{2+}$ resulting from the NO cascade, dephosphorylation of myosin light chain (MLC) by myosin light chain phosphatase (MLCP) facilitates the release of myosin from actin and smooth-muscle relaxation in NO-independent manner. ${ }^{11,31}$ Any alterations in the ionic channels, gap junctions, cGMP, cAMP and NO pathways affect the corporal smooth muscle contraction and relaxation. ${ }^{23,28,30}$

The prevalence of ED is estimated to be $50-100 \%$ in people over 70 years of age $\mathrm{e}^{25}$ and it has been increased in men below 40 years old. $^{28}$ Besides, there are limited treatment options for ED and even with the available medications, there are concerns regarding their effectiveness and adverse effects. The quest for alternative ED drugs is necessary in order to address these challenges. Therefore, the purpose of the present review was to synthesis data regarding the role of Rho-kinase in the pathogenesis of ED and the efficacy of Rho-kinase inhibitors in the treatment of ED based on original articles published in peer-reviewed journals.

\section{Methods}

\section{Search Strategies}

A systematic search of the literature was done in PubMed, Google Scholar and Scopus. A manual search was also done. The database search was carried out using different keywords such as Rho-kinase, ROCK, Rho-kinase 
inhibitors, erectile dysfunction and sexual dysfunction, then search terms were combined using either "AND" or "OR" between two or more terms (Table 1).

\section{Inclusion and Exclusion Criteria}

Included studies were original articles evaluating the role of Rho-kinase in ED pathogenesis and/or investigating novel ED therapeutic agents by targeting Rho-kinase. Articles were deemed to be eligible for inclusion if the original article was written in the English language and published between 2014 and 2019. Studies that assessed the possible anti-ED effects of Rho-kinase inhibitors using original articles with any kind of study design on animal ED model, ex-vivo model or clinical studies were included. Reviews, opinion pieces, letter to editors, conference abstracts and/or partially accessed (abstract only) articles and commentaries were excluded.

\section{Screening and Eligibility of Studies}

Potential articles have been collected from various databases and duplicates have been removed. Two investigators (KAZ and MAA) evaluated title and abstract separately on the basis of predefined inclusion criteria. This process was accompanied by the assessment and retrieval of the full texts of the relevant citations. A third investigator (BAT) was concerned for potential disputes.

\section{Data Extraction and Quality Assessment}

The extraction of data from each study was carried out using a predefined form. The two authors (KAZ and DZW) independently performed data extraction. Variables extracted from the included papers were publication year, study design, study population and/or animal model used, sample size, follow-up duration, outcomes of treatment, and risk estimates with their adjusted covariant. The quality of each paper was assessed by DZW and KAZ using the Collaborative Approach to Meta-Analysis and

Table I Databases Employed and Respective Keywords Used

\begin{tabular}{|l|l|l|}
\hline & Search Arm & $\begin{array}{l}\text { Search Terms Used (Free Text or } \\
\text { MeSH Terms) }\end{array}$ \\
\hline$\# 1$ & Rho-kinase & $\begin{array}{l}\text { Rho-kinase OR Rho-kinase inhibitors OR } \\
\text { ROCK }\end{array}$ \\
\hline$\# 2$ & $\begin{array}{l}\text { Erectile } \\
\text { dysfunction }\end{array}$ & Erectile dysfunction OR Sexual dysfunction \\
\hline
\end{tabular}

Notes: The search was made on PubMed, Scopus, Google Scholar and manual search. Search terms within the same arm were combined by "OR" and these search arm \#I and \#2 were combined by "AND".
Review of Animal Data from Experimental Studies (CAMARADES) quality assessment tool before data extraction was done. ${ }^{32}$ The quality of each paper was expressed in mean \pm standard error of mean.

\section{Results}

Out of 1067 articles, 18 articles fulfil our inclusion criteria (Figure 1). Among these, 16 were animal-based and the rest were clinical and ex-vivo studies conducted on humans and isolated tissues. In this study, we extracted data on the role of Rho-kinase in the pathogenesis and/or novel therapeutic target for the treatment of ED.

Among the included articles, five articles describe the role of Rho-kinase in ED pathogenesis using various models including cavernous nerve $(\mathrm{CN})$ crush injury, heart failure (HF)-induced ED, Vasculogenic and post-radical prostatectomy (RP) ED, diabetes-induced ED and agerelated ED. ${ }^{17,33,36}$ Ten papers describe the role of novel drugs which have been tested for the treatment of ED by targeting Rho-kinase as a potential therapy for ED. ${ }^{19,20,37,45}$ The remaining three papers describe the role of traditionally claimed plants for the treatment of ED and evaluated for their potential role in targeting Rho-kinase in animal models. ${ }^{21,46,47}$ The quality score of the included papers were ranged from 5 to 9 with an average mean articles quality score of $7.39 \pm 0.31$ (Table 2).

RhoA, ROCK I, and ROCK II expression were increased in different scenarios. ROCK II (Rho-kinase) is majorly expressed in the pathogenesis of ED. According to Alves-Lopes et al (2016), high glucose-induced ED secondary to DM increases levels of nitrotyrosine, protein oxidation/carbonylation, and Rho-kinase activity. ${ }^{34}$ Ageing has also been reported to increase the risk of developing ED as ICP/MAP ratio decreases with age. A related study showed a marked decline in eNOS protein expression with age, while the Rho-kinase protein level was increased and, in particular, the eNOS/Rho-kinase ratio decreased with age. ${ }^{35}$ Involvement of Rho-kinase in ED pathogenesis was also evaluated by animal model with HF. ${ }^{17}$ The results showed that the rats developed ED after ligation of the left anterior descending coronary artery, as demonstrated by decreased ICP/MAP responses. In addition, ROCK II and MYPT-1 phosphorylation rates increased in cavernous tissue (Table 3 ). ${ }^{17}$

Song et al (2015) also suggested that ROCK I has been involved in ED pathogenesis. In this study, ${ }^{33}$ effects in LIMK2/cofilin pathway (downstream effectors of ROCK I) following bilateral $\mathrm{CN}$ injury in male rats were evaluated. It 


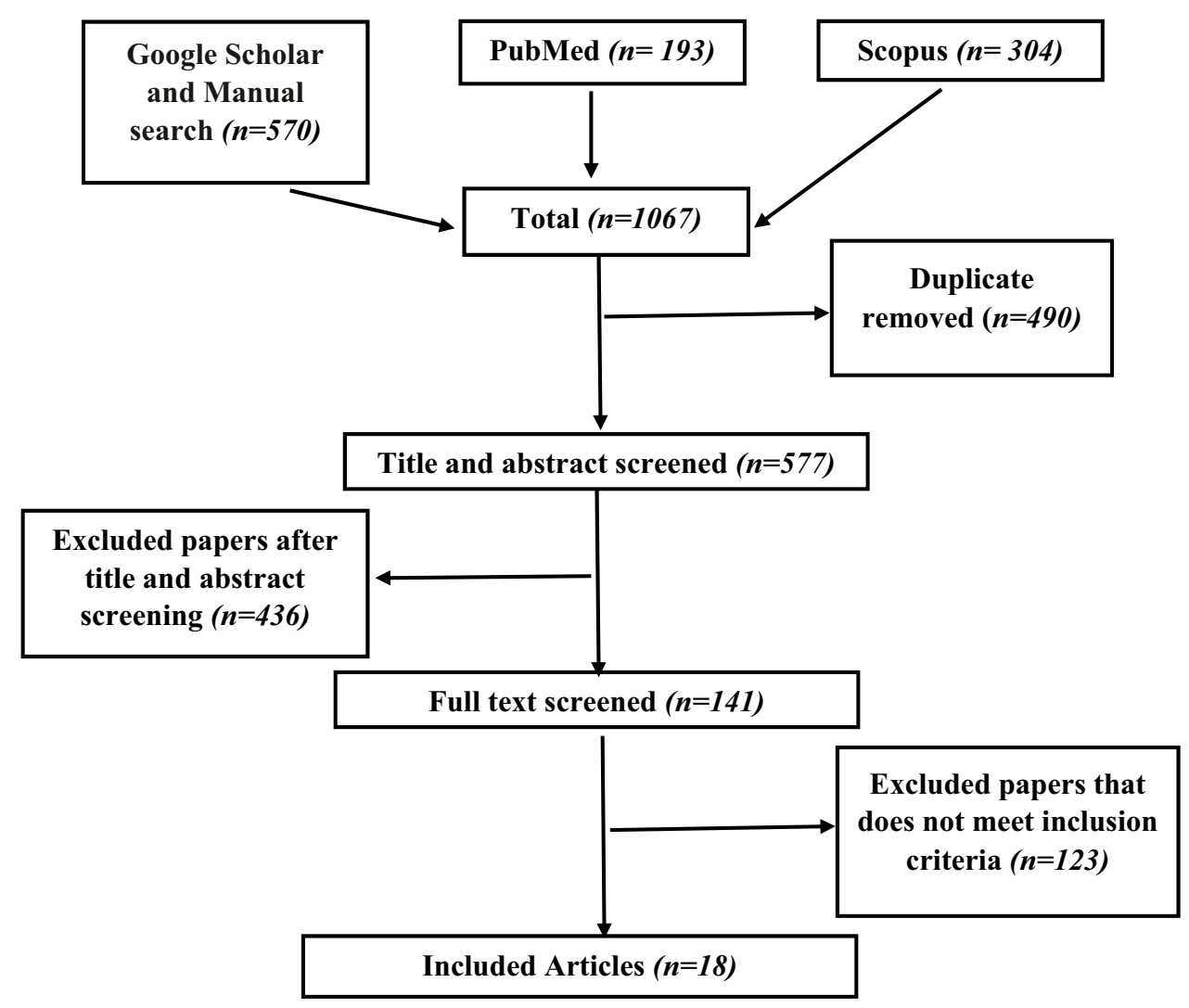

Figure I Schematic representation of the data extraction process.

has shown that after one week of $\mathrm{CN}$ injury, an upregulation of ROCK I/LIMK II/cofilin pathway was accompanied by impaired erectile response and corporal fibrosis. ${ }^{33}$

Ten novel drugs have been tested for their Rho-kinase inhibitory activity (Table 4). An ex-vivo study conducted by Uvin et al (2017) showed that the additive effects of the Rho-kinase inhibitor Y-27,632 and vardenafil on the relaxation of the corpus cavernosum (CC) tissue of patients with ED and clinical phosphodiesterase type 5 (PDE-5) inhibitor failure were assessed. According to their study, Y-27,632 induces major relaxation of $\mathrm{CC}$ in tissue strips of patients with severe ED. Besides, combination therapy has shown that mutual inhibition of Rhokinase and PDE-5 can be a successful agent in the treatment of severe ED. ${ }^{37}$

Cui et al (2017a) assessed the function of human tissue kallikrein1 (hKLK1) as an inhibitor of Rho-kinase/LIMkinase/cofilin pathway in aged transgenic rats. According to this study, ${ }^{41}$ after ED had tested and validated in older rats, hKLK1 administration has shown to reduce corporal fibrosis by inhibiting Rho-kinase activation and ameliorate age-related ED. ${ }^{41}$ Another study was also done to assess the role of fasudil (Rho-kinase inhibitor) in the treatment of ED in the $\mathrm{CN}$ crush injured rat model. ${ }^{42}$ Results from this study showed increased phosphorylation of myosin phosphatase (MYPT-1) and increased ROCK II expression in the injured groups. Inhibition of Rho-kinase in the injury plus fasudil group restored erectile responses and dynamic infusion cavernosometry parameters by alleviating increased apoptosis, decreased immune histochemical staining of alpha-smooth muscle actin ( $\alpha$-SMA) and increased caspase-3 activity. Histological and molecular dysregulations have been also alleviated by inhibition of Rho-kinase plus fasudil groups. ${ }^{42}$

$\beta_{3}$-adrenoceptor activator (Mirabegron) was also assessed for the treatment of ED by using clinical and animal models. ${ }^{45}$ The $\mathrm{CC}$ specimens were collected from patients with Peyronie's disease and ED undergoing penile prosthesis. Besides, erectile responses were evaluated invivo after intracavernosal injection (ICI) of mirabegron in anaesthetized rats. Studies have shown that mirabegron induces relaxation of phenylephrine-evoked CC contractions in a concentration-dependent manner by activating $\beta_{3}$-adrenoceptors independently of the NO-cGMP pathway and it is hypothesized that there is a near functional link between $\beta_{3}$-adrenoceptors and the RhoA/ROCK pathway. ${ }^{45}$ 
Table 2 The Quality Assessment of Individual Study Obtained According to Modified CAMARADES Checklist Items

\begin{tabular}{|c|c|c|c|c|c|c|c|c|c|c|c|}
\hline References & I & II & III & IV & v & VI & VII & VIII & IX & $\mathbf{x}$ & Total (of 10) \\
\hline 33 & I & 0 & I & I & I & 0 & I & I & I & I & 8 \\
\hline 17 & I & 0 & I & I & 0 & 0 & I & I & I & I & 7 \\
\hline 34 & I & 0 & I & I & 0 & 0 & 0 & I & I & I & 6 \\
\hline 35 & I & I & I & I & 0 & 0 & I & I & 0 & I & 7 \\
\hline 36 & I & I & 0 & I & 0 & 0 & I & I & 0 & I & 6 \\
\hline 37 & I & 1 & 0 & I & 0 & 0 & I & I & I & I & 7 \\
\hline 41 & I & I & I & I & 0 & 0 & I & I & I & I & 8 \\
\hline 19 & I & I & 0 & I & 0 & 0 & 0 & I & I & I & 6 \\
\hline 44 & I & 1 & I & I & I & 0 & I & I & 0 & I & 8 \\
\hline 40 & I & 1 & I & I & I & 0 & I & I & I & I & 9 \\
\hline 38 & I & 1 & I & I & I & 0 & 1 & I & I & I & 9 \\
\hline 42 & I & I & I & I & I & 0 & I & I & I & I & 9 \\
\hline 43 & I & 1 & 0 & I & I & 0 & I & I & I & I & 8 \\
\hline 20 & I & I & I & I & I & 0 & I & I & I & I & 9 \\
\hline 45 & I & 0 & I & I & 0 & 0 & I & I & I & I & 6 \\
\hline 46 & I & 0 & I & I & 0 & 0 & I & I & 0 & I & 6 \\
\hline 47 & I & I & I & I & I & 0 & 1 & I & I & I & 9 \\
\hline 21 & I & 0 & 0 & I & 0 & 0 & 1 & 1 & 0 & I & 5 \\
\hline
\end{tabular}

Notes: I: Publication in a peer-reviewed journal, II: Number of experimental and control groups, III: Housing and Husbandry Conditions, IV: Details of intervention/exposure group procedures, V: Random allocation to groups, VI: Concealment of allocation, VII: Blinded assessment of outcomes, VIII: Biochemical evaluations, IX: Histopathological evaluations, $\mathrm{X}$ : Statistical analysis I: Criterion is satisfied, 0 : Insufficiently described or not explained at all; the mean quality score is expressed as mean \pm standard error of the mean (SEM) and (minimum and maximum score).

Various plant extracts have been evaluated for the treatment of ED and their function in inhibiting Rho-kinase in animal models (Table 5). Eupatilin (the main compound present in Artemisia species) was assessed for its relaxant effect in-vitro and protein expression. The finding indicates Eupatilin effectively relaxed the phenylephrine-induced tone in the rabbit $\mathrm{CC}$ strips in a concentration-dependent manner. The relaxing effect of Eupatilin on $\mathrm{CC}$ smooth muscle cells may be due to activation of $\mathrm{BK}_{\mathrm{Ca}+2}$ channels and inhibition of RhoA/Rho-kinase. ${ }^{46}$ Ye et al (2019) have also reported that the effect of HongJing I (HJI), a traditional Chinese herbal remedy, in ED. Once ED was induced by bilateral cavernous nerve injury (BCNI) in rats, ICP was recorded, and histological examination was done. Results showed that RhoA, ROCK I, and ROCK II expression levels were increased with BCNI-ED induction, while HJI successfully inhibited cavernosum fibrosis and RhoA/ ROCK II signal activation. ${ }^{47}$

\section{Discussion}

ED has proved to be a significant health issue for elderly's and persons with chronic diseases. It is prevalent in people older than 40 years of age and affects their quality of life. ${ }^{23,26}$ Penile erection is a complex process in which flaccidity/rigidity within it is regulated by a balance between contractile and relaxing effects. ${ }^{48}$ Erection requires neutrally mediated relaxation of arteriolar smooth muscle and engorgement of cavernosal tissues. Current medical therapies for ED mainly perform by maximizing endogenous NO signaling. However, certain etiologies, including diabetes, are difficult to treat with current modalities. ${ }^{49}$ In addition, they are also related to increased side effects and cost. ${ }^{24}$ Therefore, the search for a new target and/or potentially effective new drugs with decreased side effects are important. Recently, research has demonstrated the importance of ROCK signaling in maintaining a flaccid penile state, and inhibition of ROCK signaling potentiates smoothmuscle relaxation in a NO-independent manner.

\section{Rho-Kinase Signaling on the Pathophysiology of Erectile Dysfunction}

The Rho/Rho-kinase pathway plays an important role in pathophysiology and progression of various diseases. ${ }^{10}$ Altered RhoA/ROCK activity in the penis is a pathogenic factor contributing to ED development. ${ }^{50}$ As shown in Figure 2, RhoA and its effector Rho-kinase have been noticed for facilitating vasoconstriction activity in the penis through inhibition of MLCP, thereby increases MLC phosphorylation and increase $\mathrm{Ca}^{2+}$ sensitivity. ${ }^{18,31,33,48} \mathrm{Ca}^{2+}$ influx into cells increases intracellular $\mathrm{Ca}^{2+}$ that is available to bind to calmodulin. This binding causes a conformational change and enable 
Table 3 Role of Rho Kinases (ROCK) in the Pathogenesis of Erectile Dysfunction

\begin{tabular}{|c|c|c|c|}
\hline $\begin{array}{l}\text { Model and Method } \\
\text { Used }\end{array}$ & Intervention and Process & Treatment Outcomes and Conclusion & References \\
\hline $\begin{array}{l}\text { Bilateral CN crush injury } \\
\text { in I0-weeks old male } \\
\text { Sprague Dawley (SD) rats. }\end{array}$ & $\begin{array}{l}\text { Electro-stimulation was performed to assess erectile } \\
\text { function. } \\
\text { Penile tissue was processed for Masson's trichrome } \\
\text { staining, Western blot and double immunofluorescent } \\
\text { staining. }\end{array}$ & $\begin{array}{l}\text { A significantly lower percent of ratio of maximal ICP/ } \\
\text { MAP and areas under the ICP curve to MAP (AUC/ } \\
\text { MAP). } \\
\text { A significantly higher expression of ROCK I/LIMK II in } \\
\text { injured groups as compared with controls. } \\
\text { Conclusion: The ROCK I/LIMK2/cofilin pathway may } \\
\text { be involved in the ED. }\end{array}$ & 33 \\
\hline $\begin{array}{l}\text { Ligation of the left } \\
\text { anterior descending } \\
\text { coronary artery (HF) } \\
\text { induced ED in rats }\end{array}$ & $\begin{array}{l}\text { Electro-stimulation was performed to assess erectile } \\
\text { function. } \\
\text { RhoA, Rho-kinase II (ROCK II) and myosin } \\
\text { phosphatase target protein I (MYPT-I) protein } \\
\text { expression and phosphorylation levels were } \\
\text { determined by Western blot analysis. }\end{array}$ & $\begin{array}{l}\text { HF rats display impaired erectile function represented } \\
\text { by decreased ICP/MAP responses. } \\
\text { HF decreased RhoA protein expression, but } \\
\text { increased ROCK II and MYPT-I phosphorylation } \\
\text { levels in cavernous tissue. } \\
\text { Conclusion: Increased responses in cavernosal tissue, } \\
\text { suggesting the involvement of ROCK signaling } \\
\text { pathway in ED genesis. }\end{array}$ & 17 \\
\hline $\begin{array}{l}\text { Streptozotocin (STZ) } \\
\text { induced DM on C57BL/6 } \\
\text { and NOXI knockout } \\
\text { mice. }\end{array}$ & $\begin{array}{l}\text { DM was induced by STZ. } \\
\text { Functional properties of internal pudendal arteries } \\
\text { (IPA) were assessed using a myograph, protein } \\
\text { expression and peroxiredoxin oxidation by Western } \\
\text { blot RNA expression by a polymerase chain reaction. }\end{array}$ & $\begin{array}{l}\text { IPA from diabetic mice displayed increased contractions } \\
\text { to phenylephrine. } \\
\text { High glucose increased ROS generation in IPA vascular } \\
\text { smooth muscle cell. } \\
\text { High glucose increased levels of nitrotyrosine, protein } \\
\text { oxidation/carbonylation, and Rho kinase activity } \\
\text { Conclusion: Rho-kinase activation, via NOXI-derived } \\
\text { ROS and downregulation of Nrf2 system, impairs IPA } \\
\text { function in DM. }\end{array}$ & 34 \\
\hline $\begin{array}{l}\text { Age-associated ED was } \\
\text { assessed in SD rats. }\end{array}$ & $\begin{array}{l}\text { Erectile response measurements were performed by } \\
\text { ICP/MAP ratio. } \\
\text { Detection of Rho-kinase and eNOS protein was done } \\
\text { by Western blot analysis. } \\
\text { Finally, correlation analyses of the association } \\
\text { between ICP/MAP and Rho-kinase, eNOS, or eNOS/ } \\
\text { Rho-kinase, as well as between age and eNOS or } \\
\text { Rho-kinase, were performed. }\end{array}$ & $\begin{array}{l}\text { The functional index ICP/MAP decreased with age in } \\
\text { SD rats. } \\
\text { The expression of eNOS protein decreased, while } \\
\text { Rho-kinase expression increased. (eNOS/Rho-kinase) } \\
\text { ratio decreased with age. } \\
\text { eNOS was found to be significantly negatively } \\
\text { correlated with age, whereas Rho-kinase was } \\
\text { positively correlated with age. } \\
\text { Conclusion: Age-associated ED was therefore } \\
\text { correlated with decreased eNOS and increased Rho- } \\
\text { kinase. }\end{array}$ & 35 \\
\hline $\begin{array}{l}\text { Vasculogenic and post- } \\
\text { radical prostatectomy } \\
\text { induced ED in human } \\
\text { subjects }\end{array}$ & $\begin{array}{l}\text { Samples were collected from individuals who undergo } \\
\text { penile surgery for Peyronie's disease and from men } \\
\text { with ED who underwent penile prosthesis } \\
\text { implantation. } \\
\text { ED was categorized into vasculogenic and post-RP } \\
\text { subtypes. } \\
\text { Penile erectile tissue samples were collected for } \\
\text { molecular analyses of protein expressions of nNOS } \\
\text { and eNOS, (Ser-14I2, (Ser-II77), (Ser-473), PDE5, } \\
\text { a-smooth muscle actin phosphomyosin phosphatase } \\
\text { target subunit I, RhoA/ROCK-I/ROCK-II by Western } \\
\text { blot. }\end{array}$ & $\begin{array}{l}\text { Vasculogenic ED was characterized by decreased } \\
\text { eNOS protein expression and eNOS and eNOS } \\
\text { phosphorylation on their activatory sites (Ser-1 I77 } \\
\text { and Ser-14I2, respectively), uncoupled eNOS, } \\
\text { upregulated PDE5 protein expression, increased } \\
\text { ROCK activity, and increased oxidative stress in } \\
\text { erectile tissue. } \\
\text { Post-RP ED was characterized by decreased eNOS } \\
\text { protein expression, increased eNOS phosphorylation } \\
\text { on its activator site (Ser- } 1412 \text { ), uncoupled eNOS, } \\
\text { down-regulated PDE5 protein expression, and } \\
\text { increased oxidative stress in erectile tissue. }\end{array}$ & 36 \\
\hline
\end{tabular}

Abbreviations: CN, cavernous nerve; DM, diabetes mellitus; ED, erectile dysfunction; eNOS, endothelial nitric-oxide synthase; ICP, intracavernosal pressure; MAP, mean arterial pressure; MLCK, myosin light chain kinase; MLCP, myosin light chain phosphatase; ROCK, Rho-associated coiled-coil-forming protein kinase. 
Table 4 Role of Rho Kinases (ROCK) Inhibitors as a Novel Therapeutic Agent for the Treatment of Erectile Dysfunction

\begin{tabular}{|c|c|c|c|}
\hline Model/Method & Intervention and Process & Treatment Outcomes and Conclusion & References \\
\hline $\begin{array}{l}\text { Relaxation of CC tissue } \\
\text { on patients with ED } \\
\text { after penile prosthesis } \\
\text { implantation. }\end{array}$ & $\begin{array}{l}\text { Human CC samples were obtained from individuals } \\
\text { undergoing penile prosthesis implantation. } \\
\text { QPCR was performed for the expression of RhoA and } \\
\text { ROCK subtypes I and } 2 \text {. } \\
\text { Immunohistochemistry staining against ROCK and } \alpha \\
\text { smooth muscle actin ( } \alpha \text {-SMA) was performed on CC of an } \\
\text { ED patient. } \\
\text { Effect of } Y-27,632 \text { and vardenafil were assessed. }\end{array}$ & $\begin{array}{l}\text { The expression of ROCK I was unchanged, while ROCK II } \\
\text { was significantly upregulated in ED patients. } \\
\text { After incubation with DMSO, Y-27,632 relaxed pre } \\
\text { contracted tissues with } 85.9 \pm 10.3 \% \text { ( } P=0.0016 \text { when } \\
\text { compared to vehicle). } \\
\text { Additive effects on the relaxation of human CC were seen } \\
\text { after pre-incubation with I } \mu \mathrm{M} \text { vardenafil. }\end{array}$ & 37 \\
\hline $\begin{array}{l}\text { DM-induced ED } \\
\text { (DMED) in rats }\end{array}$ & $\begin{array}{l}\text { Type I DM was induced by STZ. } \\
\text { Eight weeks later, the erectile function of rats was assessed } \\
\text { with an Apomorphine test. } \\
\text { Role of FTY720 was assessed } \\
\text { Metabolic parameters; erectile function; sphingosine-I- } \\
\text { phosphate receptor } 3 \text { (SIP3), protein kinase B (Akt), nitric } \\
\text { oxide (NO), and cGMP signaling pathway; corporal fibrosis; } \\
\text { apoptosis level; and Smad and non-Smad signaling pathways } \\
\text { were assessed. }\end{array}$ & $\begin{array}{l}\text { Erectile function in the DMED group was significantly } \\
\text { impaired but significantly, improved in the DMED+ FTY720 } \\
\text { group. } \\
\text { The DMED group showed inhibited activity of the SIP3- } \\
\text { Akt-NO-cGMP signalling pathway, and the inhibition was } \\
\text { partly reversed in the DMED + FTY720 group. } \\
\text { The DMED group showed serious corporal fibrosis, higher } \\
\text { apoptosis level, a higher level of Rho-kinase, LIM domain } \\
\text { kinase } 2 \text {, and cofilin. } \\
\text { FTY720 supplementation partly inhibited the activity of } \\
\text { Rho-kinase, LIM domain kinase } 2 \text { (the Smad and non-Smad } \\
\text { pathways). }\end{array}$ & 38 \\
\hline $\begin{array}{l}\text { DM-induced ED } \\
\text { (DMED) in rats }\end{array}$ & $\begin{array}{l}\text { After grouping DM was induced in rats via STZ } \\
\text { Eight weeks after DM induction, rats with ED were selected } \\
\text { via an Apomorphine test. } \\
\text { JTE-0I3 was administered intraperitoneally for treatment } \\
\text { groups. The rest were fed under the same condition. } \\
\text { Erectile function was measured by CN electro stimulation. } \\
\text { The expression levels of related signaling pathways were } \\
\text { evaluated using Western blotting, real-time PCR and } \\
\text { immunohistochemistry. }\end{array}$ & $\begin{array}{l}\text { Erectile function was significantly impaired in the DMED } \\
\text { group and was partially improved in the DMED + JTE-0I3 } \\
\text { group. } \\
\text { The expression RhoA/ROCK/P-MYPTI pathway proteins } \\
\text { were higher in the DMED group and JTE-0I3 treatment } \\
\text { significantly reduced the expression/activity of these } \\
\text { proteins. } \\
\text { Conclusion: JTE-0I3 supplementation significantly } \\
\text { ameliorated these pathological changes }\end{array}$ & 19 \\
\hline $\begin{array}{l}\text { Clinical and DM-induced } \\
\text { ED (DMED) in rats }\end{array}$ & $\begin{array}{l}\text { DM was induced by administering STZ. } \\
\text { Apomorphine was used to assess erection. } \\
\text { Role of microRNA-I4I was assessed } \\
\text { Hematoxylin-eosin (HE) staining and Masson staining, } \\
\text { Immunohistochemistry, Quantitative real-time polymerase } \\
\text { chain reaction qRT-PCR, cell culture and western bloating }\end{array}$ & $\begin{array}{l}\text { The mRNA and protein expressions of RhoA and ROCK II } \\
\text { were significantly increased while the expression of } \\
\text { microRNA-I4I was decreased in the penile tissues. } \\
\text { The microRNA-I4I expression in the microRNA-I4I } \\
\text { inhibitors + siRNA-Rho group was significantly decreased. } \\
\text { MicroRNA-I4I specifically bound to Rho-3'-UTR and } \\
\text { down-regulated the expression of the Rho gene at the post- } \\
\text { transcriptional level. }\end{array}$ & 20 \\
\hline $\begin{array}{l}\text { Partial bladder outlet } \\
\text { obstruction (PBOO) in a } \\
\text { rat model. }\end{array}$ & $\begin{array}{l}\text { After animals were grouped, PBOO was induced by } \\
\text { ligation of the urethra for } 6 \text { weeks. } \\
\text { In vivo, erectile responses were monitored by evaluating } \\
\text { ratios of ICP/MAP ratio. } \\
\text { Organ-bath studies were performed on CC strips. } \\
\text { Penises were assessed at baseline for protein expression } \\
\text { of eNOS and ROCK-II by Western blot. }\end{array}$ & $\begin{array}{l}\text { The ratio of ICP/MAP was significantly decreased in } \\
\text { obstructed rats, which was restored after treatment } \\
\text { eNOS expression in the obstructed group decreased, which } \\
\text { was improved by treatment. However, there was no } \\
\text { significant difference in the protein levels of ROCK II } \\
\text { between groups. }\end{array}$ & 40 \\
\hline
\end{tabular}

(Continued) 
Table 4 (Continued).

\begin{tabular}{|c|c|c|c|}
\hline Model/Method & Intervention and Process & Treatment Outcomes and Conclusion & References \\
\hline $\begin{array}{l}\text { Age-associated corporal } \\
\text { fibrosis in SD rats. }\end{array}$ & $\begin{array}{l}\text { Effect of human tissue kallikrein I (hKLKI) on TGR } \\
\text { harboring the hKLKI gene was fed to 4- or I8-month-old } \\
\text { rats and divided into three groups: young WTR (yWTR) as } \\
\text { the control, aged WTR (aWTR), and aged TGR (aTGR). } \\
\text { The erectile function of all rats was assessed by CN } \\
\text { electrostimulation method. } \\
\text { Masson's trichrome staining and Western blotting were } \\
\text { used to evaluate corporal fibrosis in the CC. }\end{array}$ & $\begin{array}{l}\text { The erectile function of rats in the aWTR group was } \\
\text { significantly lower than the other two groups. } \\
\text { Immunohistochemistry and Western blotting showed that } \\
\text { expression of transforming growth factor- } \beta \text { I (TGF- } \beta \text { I), } \\
\text { RhoA, ROCK I, P-MYPTI, p-LIMK2, and p-cofilin were } \\
\text { higher in the aWTR group and improved in hKLKI treated } \\
\text { groups. } \\
\text { Conclusion: hKLKI may reduce this corporal fibrosis by } \\
\text { inhibiting the activation of Rho-kinase. }\end{array}$ & 41 \\
\hline $\begin{array}{l}\mathrm{CN} \text {-crush injury in male } \\
\text { SD rats. }\end{array}$ & $\begin{array}{l}\text { Animals were grouped into } 3 \text { groups, including sham } \\
\text { surgery, CN crush injury and CN- crush injury treated with } \\
\text { fasudil. } \\
\text { Effect of Fasudil was assessed } \\
\text { Electro stimulation and dynamic infusion cavernosometry } \\
\text { were performed postoperatively. } \\
\text { Penile tissue was processed for immunohistochemistry, } \\
\text { double immune fluorescent and Masson trichrome staining, } \\
\text { TUNEL, caspase- } 3 \text { activity assay and Western blot. }\end{array}$ & $\begin{array}{l}\text { The CN crush injury group showed significantly lower ICP/ } \\
\text { MAP. } \\
\text { Rho-kinase inhibition in the injury plus fasudil group } \\
\text { restored erectile responses. } \\
\text { Conclusion: Rho-kinase inhibition in the injury plus fasudil } \\
\text { group alleviated the histological and molecular } \\
\text { dysregulation. }\end{array}$ & 42 \\
\hline $\begin{array}{l}\text { Methylglyoxal (MGO) } \\
\text { administered male rats. }\end{array}$ & $\begin{array}{l}\text { The effect of exendin-4 (Ex-4) treatment on CC dysfunction } \\
\text { was assessed. } \\
\text { Animals were grouped into four groups as control, MGO, } \\
\text { MGO + low-dose Ex-4 and MGO + high-dose Ex-4. } \\
\text { Endothelial nitric oxide synthase (eNOS), phosphorylated } \\
\text { eNOS (p-eNOS), NADPH oxidase subunit gP9Iphox } \\
\text { (NOX2), and Rho kinase (ROCK II) expressions in CC } \\
\text { were investigated by immunohistochemistry. }\end{array}$ & $\begin{array}{l}\text { In MGO administered rats, both endothelium-dependent } \\
\text { and neurogenic CC relaxations were significantly impaired. } \\
\text { The diminished response was significantly improved by } \\
\text { exendin- } 4 \text { treatment. } \\
\text { Conclusion: Exendin-4 treatment improves NO-mediated } \\
\text { CC relaxations in MGO administered rats probably by } \\
\text { inhibiting NADPH oxidase. }\end{array}$ & 43 \\
\hline $\begin{array}{l}\text { DM induced ED in a rat } \\
\text { model. }\end{array}$ & $\begin{array}{l}\text { Role of angiotensin (Ang) II inhibitor (short hairpin RNA } \\
\text { (shRNA)) was assessed. } \\
\text { ICP/MAP was measured after electrical stimulation. } \\
\text { Western blotting and quantitative RT-PCR were applied to } \\
\text { measure the expressions of RhoA, ROCK-I and II. } \\
\text { Radioimmunoassay was applied to detect the levels of Ang } \\
\text { II. }\end{array}$ & $\begin{array}{l}\text { Rats with DMED had worse ICP and MAP than Ang-II- } \\
\text { silenced rats. } \\
\text { Prolonged erectile time had shown in Ang-II-silenced rats. } \\
\text { The contraction ability was markedly improved and } \\
\text { relaxation ability was decreased in Ang-ll-silenced rats. } \\
\text { The mRNA and proteins of RhoA and ROCK II were } \\
\text { expressed in a similar way. } \\
\text { Conclusion: Ang-II silencing improves ED via down- } \\
\text { regulating the RhoA/Rho-kinase signaling pathway. }\end{array}$ & 44 \\
\hline $\begin{array}{l}\text { Patients who had } \\
\text { overactive bladder } \\
(\mathrm{OAB}) \text { and } E D \text { and } \\
\text { Mirabegron induced CC } \\
\text { relaxation in animal } \\
\text { models }\end{array}$ & $\begin{array}{l}\text { CC specimens were obtained from patients with ED and } \\
\text { Peyronie's disease undergoing penile prosthesis implantation. } \\
\text { Erectile responses were evaluated in vivo after intracavernosal } \\
\text { injection (ICl) of mirabegron in anaesthetized rats. } \\
\text { Mirabegron-elicited relaxation responses on phenylephrine- } \\
\text { induced contraction were seen in human CC (HCC) and rat } \\
\text { CC strips in isolated organ bath studies. } \\
\text { The effects of inhibitors, namely L-NAME, ODQ, methylene } \\
\text { blue, SR59230A and fasudil on mirabegron-induced relaxation, } \\
\text { responses were evaluated. } \\
\text { Immunohistochemistry was used to localize b3- } \\
\text { adrenoceptors and ROCK in CC smooth muscle cells. }\end{array}$ & $\begin{array}{l}\text { Mirabegron resulted in a relaxation of phenylephrine } \\
\text { evoked CC and SR59230A antagonized the mirabegron } \\
\text { induced relaxations in HCC and rat CC. } \\
\text { Mirabegron relaxation was enhanced by fasudil (ROCK } \\
\text { inhibitor) in rat but not in HCC strips. } \\
\text { Immunohistochemistry data showed b3-adrenoceptors } \\
\text { localized in the smooth muscle cells of the HCC and rat } \\
\text { CC. }\end{array}$ & 45 \\
\hline
\end{tabular}

Abbreviations: $\mathrm{CN}$, cavernous nerve; CC, corpus cavernosum; DM, diabetes mellitus; $E D$, erectile dysfunction; eNOS, endothelial nitric-oxide synthase; ICP, intracavernosal pressure; MAP, mean arterial pressure; MLCK, myosin light chain kinase; MLCP, myosin light chain phosphatase; ROCK, Rho-associated coiled-coil-forming protein kinase; STZ, streptozotocin. 
Table 5 Traditional Plants Used as Rho Kinases (ROCK) Inhibitors as a Therapeutic Agent for the Treatment of Erectile Dysfunction

\begin{tabular}{|c|c|c|c|}
\hline Model/Method & Intervention and Process & Treatment Outcomes/Conclusion & References \\
\hline $\begin{array}{l}\text { The ex-vivo activity } \\
\text { was done on the } \\
\text { isolated } \mathrm{CC} \text { of } \\
\text { rabbits. }\end{array}$ & $\begin{array}{l}\text { Isolated rabbit CC strips were mounted in an organ bath } \\
\text { system. } \\
\text { Effect of Eupatilin (the main compound present in } \\
\text { Artemisia species) } \\
\text { A conventional whole-cell patch-clamp technique was } \\
\text { used to measure activation of calcium-sensitive K } \\
\text { +-channel currents in human corpus cavernously } \\
\text { smooth muscle (CCSM) cells. } \\
\text { The relaxation effect of Eupatilin was evaluated by } \\
\text { cumulative addition to CC strips precontracted with } \\
\text { phenylephrine. } \\
\text { Western blotting analysis was performed to measure } \\
\text { MYPTI and protein kinase C and to evaluate the effect } \\
\text { of Eupatilin on the RhoA/Rho-kinase pathway. }\end{array}$ & $\begin{array}{l}\text { Eupatilin effectively relaxed the phenylephrine-induced } \\
\text { tone in the rabbit CC. } \\
\text { Eupatilin reduced the phosphorylation level of MYPTI at } \\
\text { Thr853 of MLCP and CPI- } 17 \text { at Thr } 38 \text {. } \\
\text { Eupatilin-induced relaxation of the CCSM cells via NO- } \\
\text { independent pathways. } \\
\text { Conclusion: The relaxation effects of eupatilin on CCSM } \\
\text { cells were partially due to activation of } \mathrm{Ca}^{+2} \text { activated } \\
\mathrm{K}^{+}\left(\mathrm{BK}_{\mathrm{Ca}^{+}+2}\right) \text { channels and inhibition of RhoA/Rho-kinase }\end{array}$ & 46 \\
\hline $\begin{array}{l}\text { Bilateral } \mathrm{CN} \text { injury } \\
(\mathrm{BCNI}) \text { induced } \mathrm{ED} \\
\text { in a rat model. }\end{array}$ & $\begin{array}{l}\text { Effect of Hongling I (HJI) was assessed } \\
\text { Rats were divided into five groups: normal control (NC), } \\
B C N I \text {-induced ED model (M), M + low-dose HJI (HL), M } \\
+ \text { medium-dose } H J I(H M) \text {, and } M+\text { high-dose } H J I(H H) \text {. } \\
\text { All groups were treated with normal saline or the } \\
\text { relevant drug for } 28 \text { days after inducing BCNI-ED. } \\
\text { Finally, ICP was recorded, Immunofluorescence staining } \\
\text { and Western blotting were applied to detect the changes } \\
\text { in fibrosis protein and RhoA, ROCK I, and ROCK II } \\
\text { expression. }\end{array}$ & $\begin{array}{l}\text { In addition, RhoA, ROCKI, and ROCK2 expression } \\
\text { levels were increased upon BCNI-ED induction. } \\
\text { HJI effectively improved the ICP in the treatment } \\
\text { groups. } \\
\text { HJI successfully inhibited cavernosum fibrosis and the } \\
\text { activation of RhoA/ROCK2 signaling. } \\
\text { Overall, these results suggest that the effects of HJI in } \\
\text { attenuating ED may be caused, at least in part, by the } \\
\text { suppression of RhoA/ROCK II signaling and alleviation of } \\
\text { fibrosis. }\end{array}$ & 47 \\
\hline $\begin{array}{l}\text { In vitro, ROCK II } \\
\text { Kinase assay was } \\
\text { done. }\end{array}$ & $\begin{array}{l}\text { Effect of Eurycoma longifolia (EL) Jack and Y- } 27,632 \\
{[(+)-(R) \text {-trans-4-(I-aminoethyl)-N-(4 pyridyl) }} \\
\text { cyclohexane carboxamide dihydrochloride] was used as } \\
\text { standard drug. } \\
\text { Luminescence was recorded using Topotecan, USA, } \\
\text { Spark } 10 \mathrm{M} \text {, multimode microplate reader. } \\
\text { Standard curve for ROCK-II enzyme was done. } \\
\text { Serial dilution and IC } 50 \text { of the AE was performed in } \\
\text { triplicate }\end{array}$ & $\begin{array}{l}\text { EL and } \mathrm{Y}-27,632 \text { as a standard showed a significant } \\
\text { inhibition for ROCK-II activity. } \\
\text { The inhibition of ROCK-II activity at } P<0.00 \mathrm{I} \text {. } \\
\text { IC } 50 \text { in ROCK-II inhibition assay of EL }(65 \mathrm{I} . \mathrm{I} \pm 32.9 \mathrm{ng} / \\
\mathrm{mL}) \text {. } \\
\text { The traditional use of } E \text {. longifolia as aphrodisiac and for } \\
\text { male sexual disorders might be partially due to the } \\
\text { ROCK-II inhibitory activity. }\end{array}$ & 21 \\
\hline
\end{tabular}

Abbreviations: CCSM, corpus cavernously smooth muscle; CN, cavernous nerve; DM, diabetes mellitus; ED, erectile dysfunction; ICP, intracavernosal pressure; MAP, mean arterial pressure; MLCK, myosin light chain kinase; MLCP, myosin light chain phosphatase; ROCK, Rho-associated coiled-coil-forming protein kinase.

complex with MLC kinase. After subsequent phosphorylation, the myosin-actin complex resulting smooth muscle contraction and a flaccid penis. ${ }^{31,48}$ In addition, upregulation of RhoA/ROCK suppresses endothelial nitric oxide synthase (eNOS) activity and it is the expression in the penis (Figure 2). Proteomics analysis on Western blot has shown that the ratio of eNOS/Rho-kinase decreased significantly due to ageing, DM and various chronic diseases. $33,35,51$

\section{Effect of Rho-Kinase Inhibition on Erectile Dysfunction}

The potential effect of RhoA/Rho-kinase mediated $\mathrm{Ca}^{2+}$ sensitization pathway in ED pathogenesis provided a logical pharmacological target for clinical application. ${ }^{15}$ Studies have demonstrated that inhibition of tonic contraction of corporal smooth muscle by intracavernosal injection or topical application of Rho-kinase inhibitors to the penis results in increased blood flow into erectile tissue and causing an erection. ${ }^{31}$ Rho-kinase inhibition restored erectile responses and dynamic infusion cavernosometry parameters by alleviating increased apoptosis, decreased immune histochemical staining of $\alpha$-SMA and increased caspase-3 activity in a NO-independent manner. Moreover, histological and molecular dysregulation were alleviated by Rho-kinase inhibition, ${ }^{14,19,41,42}$ which might improve its efficacy as compared with the currently available anti-ED drugs. However, 


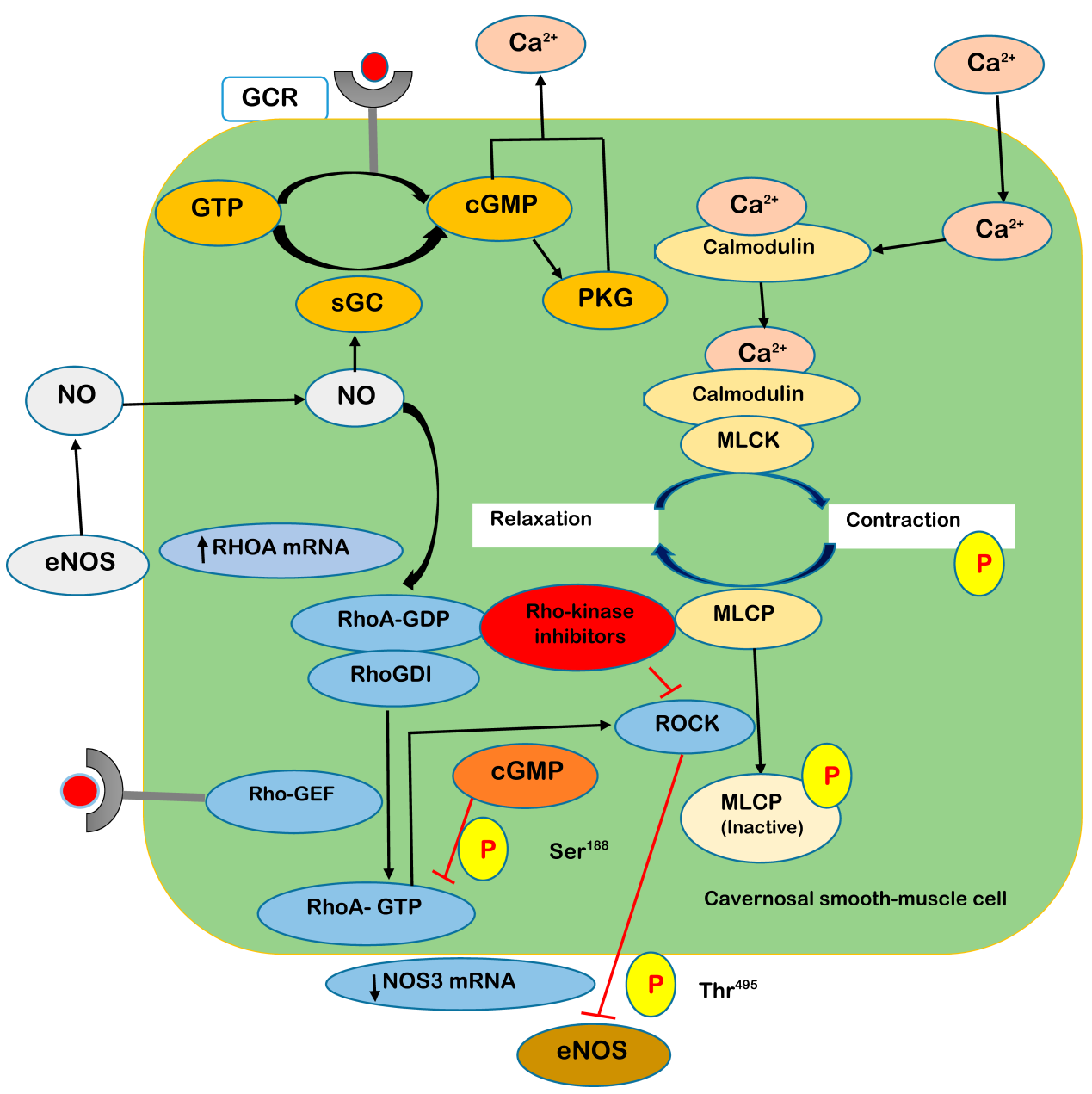

Figure 2 RhoA/Rho-kinase signaling pathway for $\mathrm{Ca}^{2+}$ sensitization in cavernosal smooth-muscle cells.

some findings showed that the vasorelaxant effect induced by the administered drugs was not mainly by the involvement of Rho-kinase inhibition, rather, by improving NO-mediated $\mathrm{CC}$ relaxations probably by inhibiting NADPH oxidase. ${ }^{43}$ Likewise, similar changes were noticed in rats with $\mathrm{CN}$ injury by involving TGF- $\beta$ - mediated fibrosis. ${ }^{19}$

\section{Strengths and Limitations}

To the best of our knowledge, this is the first systematic review that gives insight for an alternative treatment option, targeting Rho-kinase as a potential therapeutic option in the treatment of ED. However, our review did not conduct statistical analysis due to the heterogeneous nature of the included studies. Moreover, most of the reviewed papers are animal studies, which makes it difficult to conclude the models have been addressed all the pathogenic mechanisms for ED. So, further indepth studies will be required to investigate their role in
ED pathogenesis and to elucidate mechanisms for Rhokinase inhibitors.

\section{Conclusion}

Overall, our study indicates Rho-kinase can be a potential target for the treatment of ED secondary to different causes. Recently, animal and clinical studies proved that there is an up-regulation of Rho-kinase (especially ROCK II) in ED. Rho-kinase inhibitors improve erectile function in a NO-independent manner and might be a new drug family for the treatment of ED. However, more information and further detailed understanding are needed to show the ultimate effects on health outcome.

\section{Abbreviations}

$\alpha$-SMA, alpha-smooth muscle actin; CC, corpus cavernosum; $\mathrm{CN}$, cavernous nerve; $\mathrm{DM}$, diabetes mellitus; $\mathrm{ED}$, erectile dysfunction; eNOS, endothelial nitric oxide synthase; 
hKLK1, human tissue kallikrein1; HF, heart failure; ICP, intracavernosal pressure; NO, nitric oxide; MAP, mean arterial pressure; MLC, myosin light chain; MLCK, myosin light chain kinase; MLCP, myosin light chain phosphatase; MYPT, myosin phosphatase regulatory; ROCK, Rho-associated coiled-coil-forming protein kinase; STZ, streptozotocin.

\section{Author Contributions}

All authors contributed to data analysis, drafting or revising the article, gave final approval of the version to be published, and agree to be accountable for all aspects of the work.

\section{Funding}

This research did not receive any grants from funding agency in the public, commercial and not-for-profit sectors.

\section{Disclosure}

The authors declare that there are no conflicts of interest in this work.

\section{References}

1. LoGrasso PV, Feng Y Rho kinase (ROCK) inhibitors and their application to inflammatory disorders. Cur Top Med Chem. 2009;9:704-723. doi:10.2174/156802609789044452

2. Nakagawa O, Fujisawa K, Ishizaki T et al. ROCK-I and ROCK-II, two isoforms of Rho-associated coiled-coil forming protein serine/ threonine kinase in mice. FEBS Lett. 1996;392:189-193. doi:10.1016/0014-5793(96)00811-3

3. Roser AE, Tönges L, Lingor P Modulation of microglial activity by rho-kinase (rock) inhibition as therapeutic strategy in parkinson's disease and amyotrophic lateral sclerosis. Front Aging Neurosci. 2017;9:1-8. doi:10.3389/fnagi.2017.00094

4. Chen -H-H, Namil A, Severns B et al. In vivo optimization of 2,3diaminopyrazine Rho Kinase inhibitors for the treatment of glaucoma Bioorg Med Chem Lett. 2014;24:1875-1879. doi:10.1016/j. bmcl.2014.03.017

5. Fukata Y, Kaibuchi K, Amano M, Kaibuchi K Rho-Rho-kinase pathway in smooth muscle contraction and cytoskeletal reorganization of non-muscle cells. Trends Pharmacol Sci. 2001;22:32-39. doi:10. 1016/S0165-6147(00)01596-0

6. Schofield AV, Steels R, Bernard O Rho-associated coiled-coil kinase (ROCK) protein controls microtubule dynamics in a novel signaling pathway that regulates cell migration. $J$ Biol Chem. 2016;145:4362043629. 10.1074/jbc.M112.394965

7. Loirand G, Touyz RM, Touyz RM Rho kinases in health and disease. Pharmacol Rev. 2015;67:1074-1095. doi:10.1124/pr.115.010595

8. Pan P, Shen M, Yu H et al. Advances in the development of Rhoassociated protein kinase (ROCK) inhibitors. Drug Discov Today. 2013;18:1323-1333. doi:10.1016/j.drudis.2013.09.010

9. Dong M, Yan BP, Liao JK et al. Rho-kinase inhibition: a novel therapeutic target for the treatment of cardiovascular diseases. Drug Discov Today. 2010;15:622-629. doi:10.1016/j.drudis.2010.06.011

10. Hirooka Y, Shimokawa H Therapeutic potential of Rho-kinase inhibitors in cardiovascular diseases. Am J Cardiovasc Drugs. 2005;5:31-39.
11. Lu G, Hein TW, Kuo L Rho kinase-mediated coronary arteriolar constriction to endothelin-1: mechanistic implications for cardiac syndrome X. Transl Biomed. 2010;1:13-15.

12. Amin E, Dubey BN, Zhang S-C et al. Rho-kinase: regulation, (dys) function, and inhibition. Biol Chem. 2013;394:1399-1410. doi: $10.1515 / \mathrm{hsz}-2013-0181$

13. Amano M, Nakayama M, Kaibuchi K Rho-kinase/ROCK: a key regulator of the cytoskeleton and cell polarity. Cytoskeleton. 2010;67:545-554. doi:10.1002/cm.20472

14. Yin $\mathrm{H}, \mathrm{Ru} \mathrm{H}, \mathrm{Yu} \mathrm{L}$ et al. Targeting of Rho kinase ameliorates impairment of diabetic endothelial function in intrarenal artery.Int $J$ Mol Sci. 2013;14:20282-20298. doi:10.3390/ijms141020282

15. Jin L, Burnett AL RhoA/Rho-kinase in erectile tissue: mechanisms of disease and therapeutic insights. Clin Sci. 2006;110:153-165. doi: $10.1042 / \mathrm{CS} 20050255$

16. Doe C, Bentley R, Behm DJ et al. Novel Rho kinase inhibitors with anti-inflammatory and vasodilatory activities $J$ Pharmacol Exp Ther. 2007;320:89-98. doi:10.1124/jpet.106.110635

17. Rodrigues FL, Lopes RAM, Fais RS et al. Erectile dysfunction in heart failure rats is associated with increased neurogenic contractions in cavernous tissue and internal pudendal artery. Life Sci. 2016;145:9-18. doi:10.1016/j.1fs.2015.12.005

18. Rodrigues FL, Fais RS, Pereira MGAG et al. Erectile dysfunction in wistar audiogenic rats is associated with increased cavernosal contraction and decreased neuronal nitric oxide synthase protein expression. Urology. 2017;106:237.e1-237.e8. doi:10.1016/j.urology.2017.04.048

19. Liu K, Cui K, Feng H, et al. JTE-013 supplementation improves erectile dysfunction in rats with streptozotocin-induced type I diabetes through the inhibition of the rho-kinase pathway, fibrosis, and apoptosis. Andrology. 2019;0-2. doi:10.1111/andr.12716

20. Zhang Y, Jia L, Ji W, Li H MicroRNA-141 inhibits the proliferation of penile cavernous smooth muscle cells associated with down-regulation of the Rhoa/Rho kinase signaling pathway. Cell Physiol Biochem. 2018;48:348-360. doi:10.1159/000491741

21. Ezzat SM, Okba MM, Ezzat MI, Aborehab NM, Mohamed SO Rhokinase II inhibitory potential of Eurycoma longifolia new isolate for the management of erectile dysfunction. Evid Based Complement Alternat Med. 2019;2019:1-8. doi:10.1155/2019/4341592

22. Silva DF, Wenceslau CF, Mccarthy CG et al. TRPM8 channel activation triggers relaxation of pudendal artery with increased sensitivity in the hypertensive rats Pharmacol Res. 2019;147:104329. doi:10.1016/j.phrs.2019.104329

23. Burnett AL, Rodney AN, Daniel HB, et al. Erectile dysfunction AUA guideline - unabridged. Am Urol Assoc Guidel. 2018;633-641.

24. Steers WD Pharmacologic treatment of erectile dysfunction. Rev Urol. 2002;4(Suppl 3):S17-25.

25. Gareri P, Castagna A, Francomano D, Cerminara G, De Fazio P Erectile dysfunction in the elderly: an old widespread issue with novel treatment perspectives. Int $J$ Endocrinol 2014;2014:1-15. doi: $10.1155 / 2014 / 878670$

26. Shamloul R, Ghanem H Erectile dysfunction. Lancet. 2013;381:153165. doi:10.1016/S0140-6736(12)60520-0

27. Persu C, Cauni V, Gutue $S$ et al. Diagnosis and treatment of erectile dysfunction - a practical update. J Med Life. 2009;2:394-400.

28. Minh H, Nguyen T, Gabrielson AT, Hellstrom WJG Erectile dysfunction in young men: a review of the prevalence and risk factors. Sex Med Rev. 2017;5:508-520. doi:10.1016/j. sxmr.2017.05.004

29. Giuliano F, Droupy S Erectile dysfunction. Prog Urol. 2013;23:629637. doi:10.1016/j.purol.2013.01.010

30. Mobley DF, Khera M, Baum N Recent advances in the treatment of erectile dysfunction. Postgr Med J. 2017;93:679-685. doi:10.1136/ postgradmedj-2016-134073

31. Sopko NA, Hannan JL, Bivalacqua TJ Understanding and targeting the Rho kinase pathway in erectile dysfunction. Nat Public Gr. 2014;1-7. doi:10.1038/nrurol.2014.278 
32. Macleod MR, O'Collins T, Howells DW, Donnan GA Pooling of animal experimental data reveals influence of study design and publication bias. Stroke. 2004;35:1203-1208. doi:10.1161/01.STR.00001 25719.25853.20

33. Song SH, Park K, Kim SW, Paick JS, Cho MC Involvement of Rhokinase/LIM kinase/cofilin signaling pathway in corporal fibrosis after cavernous nerve injury in male rats. J Sex Med. 2015;12:1522-1532. doi:10.1111/jsm.12903

34. Alves-Lopes R, Neves KB, Montezano AC et al. Internal pudental artery dysfunction in diabetes mellitus is mediated by NOX1-derived ROS-, Nrf2-, and Rho kinase-dependent mechanisms. Hypertension. 2016;68:1056-1064. doi:10.1161/HYPERTENSIONAHA.116.07518

35. Ding Z, Shen X, Li Y Association of nNOS and Rho-kinase with ageassociated erectile dysfunction in Sprague-Dawley rats. Exp Ther Med. 2017;13:1133-1136. doi:10.3892/etm.2017.4064

36. Karakus S, Musicki B, Burnett AL Phosphodiesterase type 5 in men with vasculogenic and post-radical prostatectomy erectile dysfunction: is there a molecular difference? BJU Int. 2018;122:1066-1074. doi:10.1111/bju.14433

37. Uvin P, Albersen M, Bollen I et al. Additive effects of the Rho kinase inhibitor Y-27632 and vardenafil on relaxation of the corpus cavernosum tissue of patients with erectile dysfunction and clinical phosphodiesterase type 5 inhibitor failure. BJU Int. 2017;119:325-332. doi:10.1111/bju.13691

38. Cui K, Ruan Y, Wang T et al. FTY720 supplementation partially improves erectile dysfunction in rats with streptozotocin-induced type 1 diabetes through inhibition of endothelial dysfunction and corporal fibrosis $J$ Sex Med. 2017;14:323-335. doi:10.1016/j. jsxm.2017.01.006

39. Wang J, Zhou X, Lu H et al. Fluoxetine induces vascular endothelial growth factor/Netrin over-expression via the mediation of hypoxiainducible factor 1-alpha in SH-SY5Y cells. J Neurochem. 2016;136 (6):1186-1195. doi:10.1111/jnc.13521

40. Bastaskın T, Kaya E, Ozakca I et al. Effects of silodosin, a selective alpha-1A adrenoceptor antagonist, on erectile function in a rat model of partial bladder outlet obstruction. Neurourol Urodyn. 2017;36 (3):597-603. doi:10.1002/nau.23015

41. Cui K, Luan Y, Wang $\mathrm{T}$ et al. Reduced corporal fibrosis to protect erectile function by inhibiting the Rho-kinase/LIM-kinase/cofilin pathway in the aged transgenic rat harboring human tissue kallikrein 1. Asian J Androl. 2017;19(1):67-72. doi:10.4103/1008-682X.189209
42. Cho MC, Park K, Kim SW, Paick JS Restoration of erectile function by suppression of corporal apoptosis, fibrosis and corporal venoocclusive dysfunction with Rho-kinase inhibitors in a rat model of cavernous nerve injury. J Urol. 2015;193(5):1716-1723. doi:10.1016/ j.juro.2014.10.099

43. Dalaklioglu S, Tasatargil A, Kuscu N et al. Protective effect of exendin-4 treatment on erectile dysfunction induced by chronic methylglyoxal administration in rats. Peptides. 2018;106:1-8. doi:10.1016/j.peptides.2018.05.005

44. Li H, Jia L, Li H, Li H, Li H Angiotensin II silencing alleviates erectile dysfunction through down-regulating the Rhoa/Rho kinase signaling pathway in rats with diabetes mellitus Cell Physiol Biochem. 2018;45(1):419-427. doi:10.1159/000486919

45. Gur S, Peak T, Yafi FA et al. Mirabegron causes relaxation of human and rat corpus cavernosum: could it be a potential therapy for erectile dysfunction? BJU Int. 2016;118(3):464-474. doi:10.1111/bju.13515

46. Choo SH, Lee SW, Chae MR et al. Effects of eupatilin on the contractility of corpus cavernosal smooth muscle through nitric oxide-independent pathways. Andrology. 2017;5(5):1016-1022. doi:10.1111/andr.12397

47. Ye MY, Zhao F, Ma K et al. Effect of HongJing i in treating erectile function and regulating RhoA pathway in a rat model of bilateral cavernous nerve injury. Evid Based Complement Alternat Med. 2019;2019:1-11 doi:10.1155/2019/1083737

48. Linder AE, Webb RC, Mills TM, Ying Z, Lewis RW, Teixeira CE. Rhokinase and RGS-containing RhoGEFs as molecular targets for the treatment of erectile dysfunction. Curr Pharm Des. 2005;4029-4040.

49. Lasker GF, Maley JH, Kadowitz PJ A review of the pathophysiology and novel treatments for erectile dysfunction. Adv Pharmacol Sci. 2010; 2010.

50. Zhou Q, Mei Y, Shoji T et al. Rho-associated coiled-coil-containing kinase 2 deficiency in bone marrow-derived cells leads to increased cholesterol efflux and decreased atherosclerosis. Circulation. 2012;126 (18):2236-2247. doi:10.1161/CIRCULATIONAHA.111.086041

51. Li R, Park S-Y, Nishio $\mathrm{T}$ et al. Metabolic syndrome in rats is associated with erectile dysfunction by impairing PI3K/Akt/eNOS activity. Sci Rep. 2017;7(1):1-10. doi:10.1038/s41598-016-0028-x

\section{Publish your work in this journal}

Research and Reports in Urology is an international, peer-reviewed, open access journal publishing original research, reports, editorials, reviews and commentaries on all aspects of adult and pediatric urology in the clinic and laboratory including the following topics: Pathology, pathophysiology of urological disease; Investigation and treatment of urological disease; Pharmacology of drugs used for the treatment of urological disease. The manuscript management system is completely online and includes a very quick and fair peer-review system, which is all easy to use. Visit http://www.dovepress.com/ testimonials.php to read real quotes from published authors. 